\section{THE INTERNATIONAL SYSTEM OF WEIGHTS AND MEASURES}

BY

\section{J. M. HAMILL, M.D., D.Sc.}

Nearly a century and a half has elapsed since the International System of Weights and Measures was first inaugurated. It is also known as the metric system, because it was based on the metre, but, as will be seen later, this is no longer a correct description on account of modifications which the system has undergone since its inception. After the French Revolution the French Government decided that a rational scientific system of weights and measures which could be used internationally for all purposes was urgently necessary. Accordingly they convened a Commission of representatives of different countries, who in 1799 formulated the international system of weights and measures, or the metric system as it could then quite properly be called. The objects of the Commission were to lay down standards of length, volume, and mass* which should be interrelated and which should be based upon a natural invariable quantity independent of any arbitrary material standard. They chose as their natural quantity a unit of length which was presumed to be the one-ten-millionth part of the polar quadrant of the earth which passes through Paris. This unit of length was called the metre, and was given material expression in the form of a bar of platinum the distance between whose ends was exactly a metre. This material metre was called the "mètre des archives" and remainied the standard until 1889 . In point of fact the length of the polar quadrant was not exactly known, and the difficulty of repeating the determination of the value of the standard by reference to the definition was so great that it became necessary to legalize the length of the mètre des archives as defining the unit, so that actually the standard of length became a material one and not a natural invariable standard as was originally intended.

The standard of volume-the litre-was derived from the standard of length-the metre-or rather from the first submultiple of it-the decimetre. The litre was defined as the volume of a cube each of whose sides measured one decimetre. Since a cubic decimetre contains 1,000 cubic centimetres, the cubic centimetre became the term of description for the onethousandth part of a litre and so remained for just over 100 years, until, as will be seen later, the litre was redefined and the cubic centimetre ceased to have any derivative connexion or relationship with the litre.

The standard of mass-the kilogram-was derived from the cubic decimetre. The kilogram was defined as the mass of a quantity of water occupying the volume of one cubic decimetre at the temperature of maximum density $\left(4^{\circ} \mathrm{C}\right.$.). The material representation of this natural standard was a cylindrical piece of platinum, which was designated the "kilogramme des archives" and remained as the standard until 1889. It should be noted that the standard of mass is the kilogram and not the gramme.

The International Commission in 1799 also arranged that multiples and submultiples of the standards of length, volume. and mass should bear a decimal relationship to their respective standards in conformity. with the decimal scale of numerical notation.

\section{Reconsideration of Standards}

The position remained much as stated above during the first three-quarters of the nineteenth century. During this period the rapid development of science and technology made accurate measurements imperative, and a reconsideration of the international (metric) standards of measurement became urgent. Accordingly preliminary conferences with representatives of about thirty nations were held, and in 1875 representatives of seventeen countries subscribed to a treaty called the Convention du Mètre, by which an international organization was formed to deal with all questions relating to standards in the inter-

*Mass is the quantity of matter in a body. Weight is a force expressed as the product of the mass multiplied by the acceleration due to gravity. This latter differs at different places on the earth, and consequently the weight of $a$ body at these places differs accordingly. national system of weights and measures. Ultimately thirtytwo nations became members of the organization. The organization consists of an international authority-the Conférence Générale des Poids et Mesures-the members of which are accredited delegates of each of the thirty-two nations who joined the organization. This Conference meets normally every six years. They appoint the Comite International des Poids et Mesures, which is an executive body of eighteen members to manage the affairs of the Bureau International des Poids et Mesures between the meetings of the Conference Génerale. This Committee meets every two years, and makes representations to the General Conference or acts on authority delegated to it by the Conference. The Bureau International des Poids et Mesures is the headquarters of the organization, and is situated at Sevvres on a site which has been declared neutral territory and has been ceded by the French Government to the Conférence Générale.

The Bureau International after its formation soon came to the conclusion that the existing standards, the original standards of the archives, were capable of improvement, and it was decided to supersede them by new standards. Accordingly in 1889 the metre des archives was replaced by the existing standard, which is known as the "prototype metre." This was made as nearly as possible the same length as the mètre des archives, but it differs in several respects from the old standard. The mètre des archives was a simple bar of platinum the distance between whose ends was a metre; such a standard is known as an end-standard. The prototype metre consists of a bar of iridium-platinum alloy (10\% iridium and $90 \%$ platinum) whose cross-section is $X$-shaped and near each end on the neutral plane of the bar is ruled a fine transverse line; the distance between these two lines is a metre. Such a standard is called a line-standard. Technical improvements during the nineteenth century made it possible to rule such lines with great accuracy, so that line-standards could be made much more accurately than end-standards. When the mètre des archives was made in 1799 the reverse was the case ; line-standards could not then be made so accurately as end-standards. But the matter does not rest there. It is now possible to make endstandards having flat parallel terminal faces with a mirror-like finish of optical perfection so that by interferometric methods the length of the metre can be measured to a degree of accuracy of a wave-length of light. It is, indeed, possible to return to the 1799 Commission's ideal of a natural standard and to express the metre in terms of the wave-length of, say, the red line in the cadmium spectrum or perhaps the even more monochromatic light of an isotope of mercury. For the present, however, the prototype metre-a line-standard-remains the standard in the international system of weights and measures.

Accurate copies of the prototype metre were made and were distributed among the nations who were members of the Conférence Générale. The British copy is No. 16, and it is now preserved at the National Physical Laboratory, Teddington. It is the legal standard metre in this country. $\dagger$

An extremely important change was the redefinition of the kilogram. It had long been realized that masses could be compared with a higher degree of accuracy than volumes could be determined, and the original definition of the kilogram was abandoned because doubt had arisen whether the kilogramme des archives did conform precisely to that definition. It was obviously preferable to have a material standard of mass specifically defined rather than one defined from the unit of length through the unit of volume. Accordingly in 1889 the International Bureau constructed a new kilogram which consists of a cylinder of the same iridium-platinum alloy as that of the prototype metre, having a mass as nearly as possible equal to the kilogramme des archives. This new standard superseded the kilogram of the archives and is known as the "prototype kilogram": it is the standard kilogram at the present time. It should be emphasized that the prototype kilogram is an entirely independent standard no longer linked with the metre and consequently completely divorced from the metric system.

About forty accurate copies of the prototype kilogram were made and distributed to the countries which were members of the Conférence Générale. The British copy is No. 18 and is 
kept in a specially constructed metal container at the National Physical Laboratory, Teddington. It is the legal standard kilogram for this country. $\dagger$

\section{Cubic Centimetre versus Millilitre}

The next step taken by the International Bureau was the redefinition of the unit of volume, the litre. In 1902 the litre was defined as the volume occupied by a mass of one kilogram of water at the temperature of its maximum density $\left(4^{\circ} \mathrm{C}\right.$.) and under a pressure of one atmosphere. Since it has been redefined on a basis of the prototype kilogram it follows that the litre, like the kilogram, has been divorced from the metric system; it has now no connexion whatever with the metre. This fundamental change in definition of the litre has the effect of excluding the cubic centimetre from any derivative relationship with the litre. The thousandth part of a litre is now a millilitre and not, as originally, a cubic centimetre. The cubic centimetre should therefore never be used as an alternative to the millilitre. Although the cubic centimetre has now no derivative relationship with the litre or millilitre it is desirable to know what is the volume relationship between the litre and the cubic centimetre. This, of course, could be decided only by experiment. In 1910 the International Bureau determined this volume relationship and found that the litre as newly defined was slightly larger than the litre of the archives. Actually it was found that a litre is equal in volume to $1,000.027$ cubic centimetres; other determinations give a value of $1,000.028$ cubic centimetres. That the litre so closely approximates to the cubic decimetre is evidence of the skill with which the kilogramme des archives was constructed nearly 150 years ago.

When it is desired to convert millilitres into cubic centimetres the conversion factor will clearly be 1.000027 , and conversely when cubic centimetres are to be converted into millilitres the conversion factor will be the reciprocal of 1.000027. This conversion factor is necessary only for work requiring extreme accuracy ; for all ordinary medical purposes the conversion factor may be taken as unity. The simplicity of this conversion does not, of course, justify the use of the cubic centimetre as an alternative to the millilitre. Apart from the small but real difference in volume between the two, the fundamental reason why the cubic centimetre should not be used as an alternative to the millilitre is the fact that there is no connexion whatever between these two units. The only occasion on which the cubic centimetre can properly be used as a measure of volume is when the volume has been determined from linear measurements. It must be emphasized that the cube of a unit of linear measure as a mode of expressing volume has no derivative or cognate connexion with the litre or any of its aliquot parts.

It is sad to reflect that, although nearly half a century has elapsed since the litre was redefined, many people, including regrettably a significant proportion of the medical profession, continue incorrectly to use the cubic centimetre as an alternative to the millilitre. The international system has been legalized in this country, and the denominations of the Board of Trade standards of weight and measure which may legally be used are given in the Weights and Measures Regulations, 1907, made by the Board of Trade under the authority of the Weights and Measures Act, 1904. The litre and the millilitre have been legalized, but the cubic centimetre has not been legalized as a submultiple of the litre.

The British Pharmacopoeia, 1932, page 639, follows the legal definitions and recognizes only the litre and the millilitre. The Ministry of Health correctly uses the millilitre in the Milk (Special Designations) Order, but in the Therapeutic Substances Regulations, 1927, the cubic centimetre is used throughout instead of the correct millilitre. In Article 2 (2) of the Regulations it is stated, oddly enough, that the millilitre may be used wherever the cubic centimetre is indicated; in other words, permission is given to use the correct unit instead of the incorrect one adopted in the Regulations. The British Medical Journal has rightly insisted on the correct nomenclature in its articles, and it is to be hoped that other journals which have not yet done so will take similar action. Scientific workers in general have adopted the correct nomenclature, and all

† Weights and Measures (Metric System) Act, 1897. scientific glassware made in Britain is now graduated and marked in millilitres, not in cubic centimetres. A curious exception is the marking of hypodermic syringes in cubic centimetres. Clinicians should not lag behind the rest of the scientific world but should arrange with manufacturers to mark syringes in millilitres. Until this is done they should convert their readings into millilitres, using unity as the conversion factor. To record their readings in cubic centimetres suggests ignorance.

\section{No Longer a Metric System}

It should be clear from the foregoing why the international system of weights and measures can no longer be correctly described as a metric system. The only part of the metric system which remains is the unit of length-the metre-with its multiples and submultiples, and the squares of these to measure area, and their cubes to measure volume when this is determined from linear measurements. The unit of massthe kilogram-and the unit of volume-the litre-have been irrevocably divorced from any connexion with the metre. Metrologists cannot evade the logic of this conclusion, but some of them would fain continue to use the description "metric" mainly as a tribute to the origins of the system. When it is remembered that the metric ideal could not be accurately realized and that one of the ideals of the founders of the system was internationality, sentiment should be satisfied by the retention of this latter aspiration in the description "international system." The metric ideal has been shattered by the redefinition of the kilogram and the litre, but the ideal of internationality remains unshaken. It would seem, therefore, on grounds both of logic and of sentiment, that the proper description is the "International System of Weights and Measures."

It is interesting to note that there is a close parallel between the kilogram, the litre, and the cubic centimetre and the British weights and measures-the pound, the gallon, and the cubic inch. The pound, like the kilogram, is an independent material standard of mass; the gallon, like the litre, is a measure of volume based upon the standard of mass-one gallon is the volume of ten pounds of water. The cubic inch, like the cubic centimetre, is a measure of volume when this has been determined from linear measurements-i.e., inches. The volume relationship between the gallon and the cubic inch, like that between the litre and the cubic centimetre, has been determined experimentally-one gallon equals 277.4 cubic inches approximately.

\section{The Question of Spelling}

Finally there is the question of spelling, in which there is still a good deal of confusion. The French spelling of kilogramme, gramme, and milligramme is used in certificates issued by the National Physical Laboratory. Certain scientific societies use the English spelling, in which the final two letters, "me," are omitted. The British Pharmacopoeia, 1932, uses a mixed spelling-namely, kilogram, gramme, and milligram. The Pharmacopoeia is strictly correct in this usage, because this is the legal spelling as set out in the Weights and Measures Regulations mentioned above. This spelling was imported into the Regulations from the Weights and Measures Act, 1878, and the same spelling occurred in the Weights and Measures (Metric System) Act, 1864. The reason for its adoption in this Act is not known. From the point of view of the Pharmacopoeia the spelling "gramme" is fortunate, because it is less likely than is "gram" to be confused with "grain," especially when a writer omits to dot the " $i$ " in "grain." There is much to be said for uniformity in spelling, and if a uniform practice is adopted it should be the legal one used in the statutory regulations of the Board of Trade.

The Manchester Dental Hospital and Turner Dental School, aided by a grant of $£ 30,000$ from the trustees of the Nuffield Foundation, will undertake research into the causes of dental disease. Dr. Matthews has been appointed to the Chair of Prosthetic Dentistry and Dr. Holt to a readership in operative dentistry. The children's clinic at the hospital, by arrangement with the Manchester Education Committee, will take over the dental welfare of some 1,200 children attending three schools in the neighbourhood. It is expected that the research will continue for ten years. 